\title{
Mala praxis en las enseñanzas instrumentales: implicaciones para la formación
} docente

\author{
Malpractice in instrumental teaching: implications for teacher education
}

Alfredo Bautista

abautista@eduhk.hk

Department of Early Childhood Education

The Education University of Hong Kong

Hong Kong SAR, China

ORCID: orcid.org/0000-0002-5878-1888

Basilio Fernández Morante

basiliof@cpmvalencia.com

Conservatorio Profesional de Música de Valencia

Valencia, España

ORCID: orcid.org/0000-0002-1540-7829

doi: 10.7203/LEEME.46.18013

Recibido: 26-07-2020 Aceptado: 23-09-2020. Contacto y correspondencia: Alfredo Bautista, Department of Early Childhood Education, The Education University of Hong Kong. 10 Lo Ping Rd, Ting Kok. Tai Po, New Territories, Hong Kong SAR. China.

\section{Resumen}

Aunque la investigación sobre praxis docente es amplia, pocos estudios se han interesado por la mala praxis, es decir, por prácticas docentes incongruentes con los principios aceptados en marcos curriculares, pedagógicos y/o didácticos. El marco teórico de mala praxis docente propuesto por Herrán y González, centrado en la influencia del egocentrismo, presenta gran potencial para explicar ciertas problemáticas que tradicionalmente se han observado en las enseñanzas instrumentales en conservatorios y escuelas de música, tanto en España como en otros países. El presente estudio, basado en un análisis bibliográfico crítico de corte cualitativo, persigue dos objetivos: (1) introducir el citado marco entre los profesionales de la enseñanza instrumental, ejemplificando sus postulados centrales mediante investigaciones previas del área; y (2) proponer estrategias para prevenir la mala praxis en conservatorios y escuelas de música, fundamentadas en la literatura sobre desarrollo profesional docente. Las estrategias sugeridas implican perfilar la identidad profesional docente mediante una sólida formación pedagógica, mejorar los procedimientos de selección e inducción docente, así como fomentar el desarrollo profesional y el trabajo colaborativo. Se concluye argumentando que prevenir la mala praxis en conservatorios y escuelas de música requiere redefinir cuál es el objetivo último de las enseñanzas instrumentales en nuestra sociedad actual.

Palabras clave: Mala Praxis Docente; Conservatorio; Enseñanza Instrumental; Formación Docente.

\begin{abstract}
While research on teaching praxis is abundant, few studies have focused on analyzing instances of malpractice, that is, classroom practices that are incongruent with principles commonly accepted within curriculum, pedagogical and/or didactic frameworks. The theoretical framework of educational malpractice proposed by Herrán and González, which deals with the influence of egocentricity, holds great potential to better understand issues that have been traditionally observed in instrumental teaching within conservatories and music schools, both in Spain and other countries. The present qualitative and critical bibliographic analysis has two objectives: (1) to introduce the above-mentioned theoretical framework to instrumental teaching professionals, by illustrating its key tenets referring to prior research in the area; and (2) to propose strategies to prevent malpractice within conservatories and music schools, drawing on the teacher professional development literature. The strategies proposed involve nurturing teachers' identity as music educators via stronger pedagogical training, enhancing recruitment and induction procedures, and fostering professional development and collaborative work. We conclude by arguing that preventing malpractice in conservatories and music schools requires to rethink the ultimate goal of instrumental teaching and learning in our current society.
\end{abstract}

Key words: Educational Malpractice, Conservatories, Instrumental Teaching, Teacher Education.

@ Alfredo Bautista y Basilio Fernández Morante. The content of this article is the sole responsibility of the authors. The Revista Electrónica de LEEME and Universitat de València are not liable for any legal actions that may arise involving the article's content. Revista Electrónica de LEEME - Lista Electrónica Europea de Música en la Educación-. http://ojs.uv.es/index/php/LEEME/index ISSN: 1575-9563. Editores: Universidad de Valencia y Jesús Tejada. Visibilidad de esta revista: SCOPUS, Emerging Sources Citation Index (Clarivate), EBSCO, CINDOC (CSIC), Citefactor, COPAC, Dialnet, DICE (CSIC), DOAJ, e-revistas (CSIC), EBSCO Premier, ERIH+, Gale Cengage Learning, IN-RECS, IRESIE, LATINDEX, MIAR, OCLC Worldcat, RESH, REDIB, RILM Core Journals, SUDOC, ULRICHS. Esta revista es de acceso libre mediante licencia Creative Commons 4.0 CC by. Política de archivado: etiqueta verde SHERPA-ROMEO. 


\section{Introducción y revisión de la literatura: el concepto de mala praxis}

El término praxis proviene de un concepto griego $(\pi \rho \tilde{\alpha} \xi 1 \varsigma)$ que hace referencia a la práctica (la acción), y se utiliza para denominar el proceso por el cual una teoría pasa a formar parte de la experiencia vivida. Como indican Pérez Porto y Gardey (2018), la praxis constituye una etapa necesaria y fundamental en el desarrollo y construcción de conocimientos válidos. A diferencia de la teoría, la cual se basa esencialmente en abstracciones intelectuales, la praxis se manifiesta cuando las ideas son experimentadas o practicadas en la vida real, permitiendo por tanto observar y reflexionar sobre sus consecuencias y/o resultados. Villegas (2016) señala que la praxis se refiere al actuar responsable, independiente y guiado por las ideas del hombre para satisfacer sus necesidades, tanto materiales como espirituales, y de esta forma crear las condiciones para poder construirse hacia lo humano.

En este marco, el concepto de mala praxis remite a la existencia de negligencias, errores, o desviaciones respecto a la práctica convencional, concretamente en el ejercicio de actividades profesionales. Por lo general, dicho concepto se utiliza en el ámbito de profesiones de carácter asistencial, haciendo alusión a la responsabilidad de sus profesionales cuando actúan de manera inapropiada. Cuando un médico, un contable, o un abogado no procede con arreglo a los criterios técnicos establecidos en su área, incurriría en la mala praxis, pudiendo causar daños o efectos no deseados a terceras personas. Aunque pueden darse casos de tipo criminal, es preciso señalar que la mala praxis no suele ser intencional; por graves que puedan ser sus consecuencias, por lo general se trata de negligencias o errores (Pérez Porto y Gardey, 2018).

Por ejemplo, en el campo de la medicina, se considera que existe mala praxis cuando se provoca un daño en el cuerpo o en la salud de la persona sea este daño parcial o total, limitado en el tiempo o permanente, "como consecuencias de un accionar profesional realizado con imprudencia o negligencia, impericia en su profesión o arte de curar o por inobservancia, de los reglamentos o deberes a su cargo con apartamiento de la normativa legal aplicable" (Silva, 2008, p.121). Los estudios sobre mala praxis médica han tenido un desarrollo considerable en las últimas décadas, sobre todo en relación con cuestiones jurídico-legales (Dumitrescu, 2019), jugando un rol central en la mejora de las prácticas y en la formación de profesionales sanitarios.

En el terreno de la educación, es evidente que también existe un margen considerable para la mala praxis, aunque sus efectos no sean tan inmediatos y/o tangibles como en medicina. Sin embargo, resulta sorprendente que los investigadores ${ }^{1}$ educativos no se hayan centrado en documentar y analizar las negligencias o errores docentes, es decir, aquellas prácticas desviadas

\footnotetext{
${ }^{1}$ A lo largo del artículo, se utiliza el género masculino en referencia a los sexos masculino y femenino, de forma indistinta.

@ Alfredo Bautista y Basilio Fernández Morante. The content of this article is the sole responsibility of the authors. The Revista Electrónica de LEEME and Universitat de València are not liable for any legal actions that may arise involving the article's content. Revista Electrónica de LEEME - Lista Electrónica Europea de Música en la Educación-. http://ojs.uv.es/index/php/LEEME/index ISSN: 1575-9563. Editores: Universidad de Valencia y Jesús Tejada. Visibilidad de esta revista: SCOPUS, Emerging Sources Citation Index (Clarivate), EBSCO, CINDOC (CSIC), Citefactor, COPAC, Dialnet, DICE (CSIC), DOAJ, e-revistas (CSIC), EBSCO Premier, ERIH+, Gale Cengage Learning, IN-RECS, IRESIE, LATINDEX, MIAR, OCLC Worldcat, RESH, REDIB, RILM Core Journals, SUDOC, ULRICHS. Esta revista es de acceso libre mediante licencia Creative Commons 4.0 CC by. Política de archivado: etiqueta verde SHERPA-ROMEO.
} 


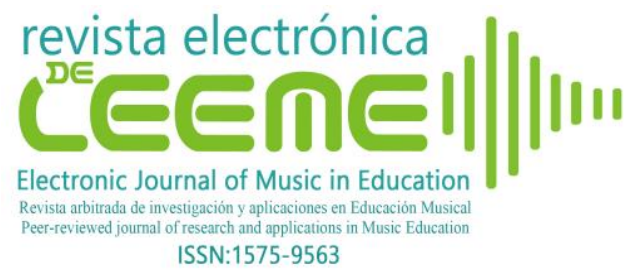

Alfredo Bautista y Basilio Fernández Morante Mala praxis en las enseñanzas instrumentales: implicaciones para la formación docente (Revista Electrónica de LEEME) Número 46, pp. 240-26 ojs.uv.es/index.php/LEEME/index

de los principios teóricos comúnmente aceptados en marcos curriculares, pedagógicos y/o didácticos. En sus escritos pioneros sobre educational malpractice en el contexto norteamericano, Funston (1981) y Foster (1986) comenzaron a plantear que los docentes debían ser considerados responsables del impacto de sus acciones sobre los estudiantes, argumentando que la atribución de responsabilidades jurídicas tendría un impacto positivo sobre la calidad y la adecuación de las prácticas docentes. Tras dichos trabajos, la escasa literatura sobre mala praxis educativa se ha centrado fundamentalmente en documentar casos de mala conducta y corrupción extrema dentro de sistemas educativos. Por ejemplo, Tanaka (2001) documentó casos de soborno, acoso sexual y explotación de estudiantes, planteando que las prácticas corruptas en ambientes educativos suelen ser el resultado de relaciones desiguales de poder, donde el docente se sitúa en una posición superior.

Posteriormente, Heyneman (2004) se centró en analizar las causas de los diferentes casos de mala conducta docente descritos en la literatura educativa hasta la fecha. Identificó concretamente nueve tipos de casos: (1) Recibir objetos materiales, regalos o favores a cambio de altas calificaciones, evaluaciones positivas o aceptación en programas; (2) Asignar notas o evaluaciones sesgadas, con base en elementos de tipo étnico o racial, cultural, social, u otros atributos personales; (3) Obligar a los estudiantes a adoptar los valores personales o la filosofía del profesor; (4) Revelar información confidencial del estudiantado; (5) Discriminar, acosar o abusar sexualmente del alumnado; (6) Adoptar manuales o materiales inapropiados para recibir incentivos o regalos del fabricante; (7) Forzar al alumnado a adquirir materiales didácticos comercializados por el propio profesorado; (8) No denunciar casos de mala conducta de otros profesionales, el tratamiento injusto de los estudiantes, o las malas prácticas de aula; y (9) Utilizar instalaciones escolares públicas para beneficios comerciales privados. Más recientemente, Martin (2016) ha documentado otros problemas de mala praxis como el absentismo docente, el cobro de tasas ilegales a los estudiantes y sus familias, así como la falta de integridad académica (e.g., plagios, falsificación de evidencias). Otros estudios se han centrado en analizar las consecuencias legales de la mala praxis educativa a nivel institucional, proponiendo estrategias efectivas de actuación para combatir malas prácticas en escuelas y universidades (Hallak y Poisson, 2007).

Dentro del contexto español, mientras que existen numerosas investigaciones dedicadas a ilustrar casos de buenas prácticas en diversos entornos educativos (e.g., Castillo, Ramos Corpas, y Moral, 2020; Escudero, 2009; Zabalza, 2012), el tema de la mala praxis docente ha sido escasamente investigado. Hasta donde llega nuestro conocimiento, tras una extensa revisión de la literatura, Agustín de la Herrán y sus colaboradores son los únicos investigadores que han abordado esta temática en el ámbito docente nacional (Herrán, 1995, 2011, 2017; Herrán y Fortunato, 2019; Herrán y González, 2002, 2003). Para Herrán y González, (2002), la mala praxis docente o educativa comprendería "aquellas acciones de enseñanza realizadas desde individuos, equipos, centros y sistemas en general que podrían frenar, bloquear o sesgar, tanto su propio desarrollo profesional, como la formación de sujetos concretos de educación y la @ Alfredo Bautista y Basilio Fernández Morante. The content of this article is the sole responsibility of the authors. The Revista Electrónica de LEEME and Universitat de València are not liable for any legal actions that may arise involving the article's content. Revista Electrónica de LEEME - Lista Electrónica Europea de Música en la Educación-. http://ojs.uv.es/index/php/LEEME/index ISSN: 1575-9563. Editores: Universidad de Valencia y Jesús Tejada. Visibilidad de esta revista: SCOPUS, Emerging Sources Citation Index (Clarivate), EBSCO, CINDOC (CSIC), Citefactor, COPAC, Dialnet, DICE (CSIC), DOAJ, e-revistas (CSIC), EBSCO Premier, ERIH+, Gale Cengage Learning, IN-RECS, IRESIE, LATINDEX, MIAR, OCLC Worldcat, RESH, REDIB, RILM Core Journals, SUDOC, ULRICHS. Esta revista es de acceso libre mediante licencia Creative Commons 4.0 CC by. Política de archivado: etiqueta verde SHERPA-ROMEO. 


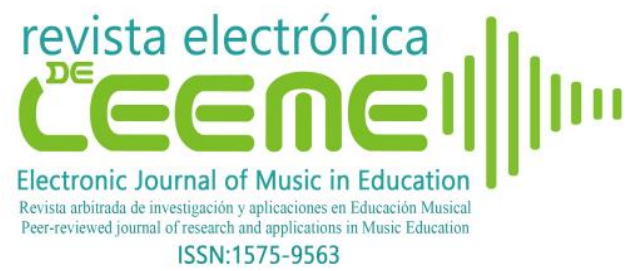

propia sociedad" (p. 101). Los autores plantean que el estudio detallado de dichas acciones es de gran utilidad desde el punto de vista formativo, pues permite al profesorado (tanto en formación como en ejercicio) crecer como docentes a partir de la reflexión y análisis sobre las (malas) prácticas, tanto propias como ajenas.

Herrán y González (2002) desarrollaron un interesante marco teórico para el estudio de la mala praxis de aula ${ }^{2}$. Con base en la teoría fundamentada (Glasser, 2001) y en la indagaciónacción como perspectiva metodológica (Socorro, 2011), los autores proponen la existencia de dos grandes tipos de errores docentes:

1. Los errores técnicos, debidos a la falta de conocimiento o al conocimiento inadecuado del docente, como consecuencia de una formación de baja calidad. Estos resultarían, por ejemplo, en programaciones didácticas mal elaboradas, en falta de dominio del contenido a enseñar, desconocimiento de las estrategias de enseñanza apropiadas, escasa claridad metodológica, o en procedimientos de evaluación inadecuados.

2. Los errores egóticos, o relativos al ego del propio docente (nótese que los autores no se basan en teorías psicoanalíticas). Estos errores están frecuentemente relacionados, combinados y/o solapados con los errores técnicos, aunque su origen no se sitúa en los conocimientos relativos a la enseñanza, sino en variables personales como las actitudes del docente, su mentalidad, carácter o motivaciones, afectando todo ello a sus procesos de pensamiento, razonamiento y comunicación. Los autores plantean que los errores egóticos son producto de la interacción entre factores de personalidad y escasa formación, y que suelen ser interpretados como resultado del ser de cada docente y/o como vicios profesionales.

En sus diversas investigaciones (e.g., Herrán, 1995, 2011, 2014; Herrán y Fortunato, 2019; Herrán y González, 2002, 2003; Socorro y Herrán, 2012), Herrán y sus colaboradores han venido planteando que el egocentrismo es un condicionante crucial de la conciencia. En su marco inicial, Herrán y González (2002) proponen que buena parte de los problemas de mala praxis en las aulas tienen su origen en el egocentrismo docente, que califican como punto ciego de la enseñanza y como el principal lastre del desarrollo profesional del profesorado. Conceptualizan el ego como la característica más destacada de la inmadurez personal y social del adulto, y como la parte del yo que impide la evolución del docente. Proponen un listado de listado de aproximadamente dos mil posibles errores docentes (e.g., inmovilismo metodológico, no tomar en cuenta las preferencias y opiniones del alumnado, pretender que todos aprendan igual y vayan al mismo ritmo, poner en evidencia a los estudiantes no cumplen las expectativas). Dicho listado, diseñado a modo de checklist, persigue ayudar al profesorado a

\footnotetext{
${ }^{2}$ Nótese que Herrán y González (2002) utilizan frecuentemente el término malpraxis.

@ Alfredo Bautista y Basilio Fernández Morante. The content of this article is the sole responsibility of the authors. The Revista Electrónica de LEEME and Universitat de València are not liable for any legal actions that may arise involving the article's content. Revista Electrónica de LEEME - Lista Electrónica Europea de Música en la Educación-. http://ojs.uv.es/index/php/LEEME/index ISSN: 1575-9563. Editores: Universidad de Valencia y Jesús Tejada. Visibilidad de esta revista: SCOPUS, Emerging Sources Citation Index (Clarivate), EBSCO, CINDOC (CSIC), Citefactor, COPAC, Dialnet, DICE (CSIC), DOAJ, e-revistas (CSIC), EBSCO Premier, ERIH+, Gale Cengage Learning, IN-RECS, IRESIE, LATINDEX, MIAR, OCLC Worldcat, RESH, REDIB, RILM Core Journals, SUDOC, ULRICHS. Esta revista es de acceso libre mediante licencia Creative Commons 4.0 CC by. Política de archivado: etiqueta verde SHERPA-ROMEO.
} 
tomar conciencia de actitudes y conductas basadas en el ego, así como ayudarles a descubrir qué repercusiones puede tener su forma de ser y de actuar sobre los demás (e.g., estudiantes, colegas, padres) (Socorro y Herrán, 2012). Con base en técnicas de observación sistemática y entrevistas, los autores muestran que el egocentrismo puede superarse mediante un largo y complejo proceso de reflexión y toma de conciencia pedagógica. Dicho proceso implica un compromiso con la madurez personal centrada en el cambio interior, el autoconocimiento y la coherencia, desde la indagación y el incremento de reflexividad, esenciales para poder educar desde la ejemplaridad (Herrán, 2011).

\section{Objetivos y metodología}

El marco teórico de mala praxis docente propuesto por Herrán y González (2002) presenta, a nuestro juicio, gran potencial para explicar ciertas problemáticas que tradicionalmente se han observado en las enseñanzas instrumentales en conservatorios y escuelas de música, tanto en España como en otros países. Dichas enseñanzas son proclives a esconder casos de malas prácticas de diversa naturaleza debido a su carácter eminentemente individual y a su fuerte arraigo a principios instruccionales del siglo XIX (Tregear et al., 2016), incluyendo casos extremos de violencia psicológica y abuso (Fernández-Morante, 2018). Las clases de instrumento han sido caracterizadas como un "jardín secreto" (Burwell, Carey y Bennett, 2017), donde impera un fuerte individualismo (incluso aislamiento) docente, que favorece el egocentrismo y que en ocasiones desemboca en mala praxis, como plantean Herrán y González (2002). Además, las carencias en la formación pedagógica que existen todavía en el profesorado de los conservatorios y escuelas de música en España, pese a los numerosos cambios legislativos en las ultimas décadas, hacen que los docentes continúen enseñando basándose esencialmente en sus concepciones o teorías implícitas, y en buena medida por ensayo y error, en muchas ocasiones reproduciendo los esquemas que aprendieron de sus propios docentes, incluyendo los errores y malas prácticas (Pozo, Pérez Echeverría, Torrado y López-Í̃̃iguez, 2020).

El presente estudio persigue dos objetivos. El primero es introducir el marco teórico de mala praxis docente propuesto por Herrán y González (2002) entre los profesionales de la enseñanza instrumental, ejemplificando algunos de los postulados centrales de dicho marco a partir de investigaciones realizadas en conservatorios y escuelas de música, tanto nacionales como internacionales. Con ello, se pretende fomentar una comprensión profunda y situada de las relaciones entre egocentrismo y malas prácticas en contextos de enseñanza y aprendizaje instrumental. Por su parte, el segundo objetivo es delinear implicaciones para la formación del profesorado y posibles estrategias para prevenir la mala praxis entre los profesionales de enseñanzas instrumentales, fundamentadas en la literatura en desarrollo profesional docente.

@ Alfredo Bautista y Basilio Fernández Morante. The content of this article is the sole responsibility of the authors. The Revista Electrónica de LEEME and Universitat de València are not liable for any legal actions that may arise involving the article's content. Revista Electrónica de LEEME - Lista Electrónica Europea de Música en la Educación-. http://ojs.uv.es/index/php/LEEME/index ISSN: 1575-9563. Editores: Universidad de Valencia y Jesús Tejada. Visibilidad de esta revista: SCOPUS, Emerging Sources Citation Index (Clarivate), EBSCO, CINDOC (CSIC), Citefactor, COPAC, Dialnet, DICE (CSIC), DOAJ, e-revistas (CSIC), EBSCO Premier, ERIH+, Gale Cengage Learning, IN-RECS, IRESIE, LATINDEX, MIAR, OCLC Worldcat, RESH, REDIB, RILM Core Journals, SUDOC, ULRICHS. Esta revista es de acceso libre mediante licencia Creative Commons 4.0 CC by. Política de archivado: etiqueta verde SHERPA-ROMEO. 
La metodología adoptada consiste en un análisis bibliográfico crítico, de corte cualitativo (Gupta, 2018; Young, 2001). De acuerdo con Boote y Beile (2005), revisiones teóricas de esta naturaleza pueden ser generadoras de nuevos discursos y preguntas de investigación, contribuyendo a abrir nuevas áreas potenciales de conocimiento. En última instancia, por tanto, se pretende identificar territorios epistemológicos y conceptuales poco explorados hasta la fecha y fomentar el desarrollo de la investigación en educación musical.

\section{Mala praxis en enseñanzas instrumentales: ¿Cómo se manifiestan los síntomas egóticos entre el profesorado de instrumento?}

A partir de un cuidadoso trabajo observacional en diversas etapas educativas, desde la Educación Infantil hasta el Doctorado, Herrán y González (2002) identifican diversos síntomas egóticos que subyacen en la mala praxis docente. Plantean que dichos síntomas dan lugar a la mayor parte de errores docentes, afectando negativamente sobre el diseño y desarrollo de la comunicación educativa y las relaciones profesionales, creando por tanto numerosas dificultades en los contextos de enseñanza/aprendizaje. En este apartado, se ilustran los cuatro síntomas egóticos más fácilmente observables en el ámbito de las enseñanzas instrumentales. Pese a tener rasgos diferenciadores, los síntomas descritos están estrechamente relacionados entre sí, como parte de lo que Herrán y González (2002) denominan síndrome egótico. Se comienza cada sección presentando la definición del síntoma, según los autores, y a continuación se ejemplifica recurriendo a investigaciones realizadas en contextos de enseñanza y aprendizaje instrumental.

\subsection{El narcisismo: la distinción y superioridad del instrumentista}

Según Herrán y González (2002), el síntoma egótico del narcisismo hace que la persona se concentre absolutamente en ella misma para auto admirarse. El narcisismo se caracteriza por actitudes de distinción con respecto a personas o entornos igualmente narcisistas, y actitudes de distanciamiento hacia quienes no lo son. Las actitudes de distinción hacen que el individuo perciba la realidad desde una perspectiva de superioridad, que a su vez justifica el distanciamiento en sus actividades sociales. En el terreno docente, el profesor narcisista suele expresar sentimientos de auto importancia, soberbia y auto complacencia.

Los conservatorios han estado marcados históricamente por su exigencia y disciplina, así como por la competitividad explícita y deliberada (Miksza, Evans y McPherson, 2019a). La mayoría de estudiantes abandonan el conservatorio en algún punto de los estudios, a modo de selección natural (Pozo et al., 2020). En un contexto altamente demandante, donde las ideas de excelencia y de talento predominan desde el comienzo de los estudios (se exige superar una prueba de aptitudes para acceder a la enseñanza oficial), es común que los supervivientes del sistema desarrollen sentimientos de distinción y superioridad, que en ciertos casos podrían desembocar en actitudes narcisistas (Musumeci, 2006). Asimismo, la investigación muestra que

@ Alfredo Bautista y Basilio Fernández Morante. The content of this article is the sole responsibility of the authors. The Revista Electrónica de LEEME and Universitat de València are not liable for any legal actions that may arise involving the article's content. Revista Electrónica de LEEME - Lista Electrónica Europea de Música en la Educación-. http://ojs.uv.es/index/php/LEEME/index ISSN: 1575-9563. Editores: Universidad de Valencia y Jesús Tejada. Visibilidad de esta revista: SCOPUS, Emerging Sources Citation Index (Clarivate), EBSCO, CINDOC (CSIC), Citefactor, COPAC, Dialnet, DICE (CSIC), DOAJ, e-revistas (CSIC), EBSCO Premier, ERIH+, Gale Cengage Learning, IN-RECS, IRESIE, LATINDEX, MIAR, OCLC Worldcat, RESH, REDIB, RILM Core Journals, SUDOC, ULRICHS. Esta revista es de acceso libre mediante licencia Creative Commons 4.0 CC by. Política de archivado: etiqueta verde SHERPA-ROMEO. 


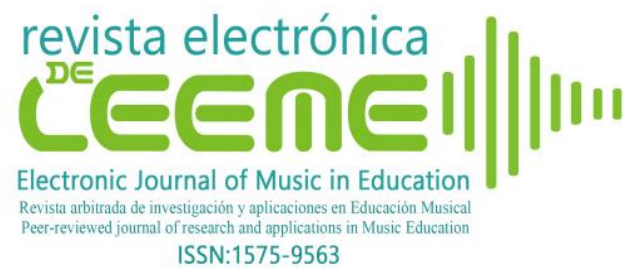

la decisión de embarcarse en estudios artísticos de naturaleza interpretativa es, a menudo, el resultado del deseo de recibir reconocimiento y alabanza social (Miksza, Evans y McPherson, 2019b), mezclado con cierto grado de impulsos exhibicionistas (Persson, 2001). El perfil profesional de intérprete implica inevitablemente exposiciones públicas, a modo de representaciones de sí mismo, que pueden activar fácilmente esas tendencias exhibicionistas que, a su vez, constituyen los componentes esenciales del narcisismo (Szabolcs, Sándor y László, 2017).

Los sentimientos de distinción y superioridad del alumno pueden magnificarse una vez éste se convierte en docente, especialmente en un marco maestro-aprendiz donde el profesor suele ser considerado un modelo a imitar (Jørgensen, 2000). La formación instrumental se produce en estrecho contacto personal, donde muchos estudiantes buscan de forma permanente al profesor como espejo en que mirarse. Alrededor de ciertos docentes de instrumentoespecialmente en niveles superiores-suele existir una especie de halo de veneración, y el alumno nunca olvida que siempre estará en deuda con su maestro (Kogan, 1987).

Las dinámicas entre profesorado dominantes y alumnado subordinados a su maestro pueden fácilmente desembocar en casos de mala praxis, con conductas que reflejan actitudes de superioridad y distanciamiento del docente hacia el alumnado. A menudo, las clases de instrumento se tornan en un puro monólogo del profesor, quien se limita a identificar los errores del alumno y a darle instrucciones directas para mejorar, a veces con gran dureza y despotismo, como se espera de un genio (Judge, 2009), sin espacio para intervenciones, preguntas, o cuestionamiento alguno por parte del estudiante ${ }^{3}$, con el consiguiente impacto negativo sobre su metacognición (Torrado y Pozo, 2008).

\subsection{Egocentrismo: la centralidad del profesorado de instrumento}

Otro síntoma importante es el egocentrismo, que en los docentes se manifiesta en dificultades para integrar su tarea en coordenadas amplias. El profesor egocéntrico solo suele prestar atención a lo propio, o a lo que considera propio, mostrando desinterés por todo lo demás (Herrán y González, 2002). Actividades cuyos beneficiarios son ajenos al círculo directo, como proyectos colaborativos realizados con estudiantes de otros docentes o de otros departamentos (por ejemplo, para fomentar la interdisciplinariedad o la integración curricular), tienden a ser ignoradas. Asimismo, el profesor egocéntrico muestra dificultades para realizar autocrítica y aceptar críticas ajenas, y suele manifestar una menor capacidad para empatizar con

\footnotetext{
${ }^{3}$ Existen numerosos videos de clases magistrales de reconocidos intérpretes que ilustran lo dicho. Por ejemplo, en el siguiente link de YouTube, el lector interesado puede observar el estilo pedagógico del maestro Andrés Segovia impartiendo clases de guitarra a estudiantes de nivel avanzado: https://www.youtube.com/watch?v=XZDA1crTi9A
} 
compañeros, estudiantes y/o familias. En la práctica, estos docentes solo suelen contemplar ideas, conductas, y/o actitudes que confirmen sus propios planteamientos.

Desde hace décadas, la investigación etnográfica ha venido documentando casos de profesorado de conservatorios que claramente manifiesta actitudes y conductas egocéntricas, las cuales desembocan en instancias de mala praxis (e.g., Nettl, 1995). Ciertos docentes de instrumento suelen situarse como centro de las enseñanzas musicales, en la cima de la pirámide de su institución, restando constantemente importancia a las otras materias del currículo y haciendo que pasen a un segundo plano para los estudiantes. Por ejemplo, el estudio de Bújez (2007) mostró que los horarios, espacios y actividades en los conservatorios superiores de música "se organizan pensando en el profesorado, que disfruta así de un ambiente favorable de trabajo, pero no en el alumnado, al que le son impuestos todos los aspectos" (p.245). En este contexto, es difícil observar proyectos conjuntos entre discentes de distintos docentes, o trabajos colaborativos entre profesorado de distintas materias (Bautista, 2020).

El egocentrismo del maestro suele aumentar en función de su prestigio y reconocimiento en el panorama escénico, e incluso de su filiación a ciertas escuelas interpretativas (Tregear et al., 2016). Dicho estatus de superioridad puede ser utilizado para justificar (incluso imponer) sus propios planteamientos, que se muestran únicos y sobre los que no se aceptan críticas (Nettl, 1995). La investigación ha mostrado que las dinámicas de trabajo en clases de instrumento tienden a estar monopolizadas por los docentes, quienes acostumbran a aceptar preguntas sin respuesta, respuestas superficiales, o incluso a contestar ellos mismos a las preguntas planteadas (Burwell, 2005). En muchas ocasiones, los únicos parámetros que se consideran durante el aprendizaje del repertorio son los marcados por el maestro: su edición, su digitación, su técnica, su tempo... en definitiva, su versión. Implícitamente, se acepta que el aprendizaje musical ha de ajustarse a las expectativas y requerimientos del maestro.

\subsection{Proxemia psíquica: "mi técnica", "mi estilo", "mis alumnos"...}

La proxemia psíquica hace referencia al espacio mental donde la necesidad vital de todo ser humano de desenvolverse en un espacio personal y propio se convierte en obsesión por la posesión y la propiedad (Herrán y González, 2002). El docente manifiesta proxemia psíquica cuando muestra sentimientos excesivos de pertenencia sobre elementos o aspectos relacionados con su actividad profesional (e.g., personas, materiales, enfoques). Este tipo de actitudes y conductas proxémicas son habituales entre docentes de instrumento, dado que sus métodos pedagógicos y didácticos suelen dejarse a su entera disposición, siendo rara vez supervisados o evaluados (Bautista y Fernández-Morante, 2018).

El individualismo artístico está en la base de la filosofía educativa de muchos conservatorios y escuelas de música (Miksza et al., 2019a). El profesorado de instrumento no suele introducir diferentes recursos técnicos o estilísticos al alumnado, sino que se limita a @ Alfredo Bautista y Basilio Fernández Morante. The content of this article is the sole responsibility of the authors. The Revista Electrónica de LEEME and Universitat de València are not liable for any legal actions that may arise involving the article's content. Revista Electrónica de LEEME - Lista Electrónica Europea de Música en la Educación-. http://ojs.uv.es/index/php/LEEME/index ISSN: 1575-9563. Editores: Universidad de Valencia y Jesús Tejada. Visibilidad de esta revista: SCOPUS, Emerging Sources Citation Index (Clarivate), EBSCO, CINDOC (CSIC), Citefactor, COPAC, Dialnet, DICE (CSIC), DOAJ, e-revistas (CSIC), EBSCO Premier, ERIH+, Gale Cengage Learning, IN-RECS, IRESIE, LATINDEX, MIAR, OCLC Worldcat, RESH, REDIB, RILM Core Journals, SUDOC, ULRICHS. Esta revista es de acceso libre mediante licencia Creative Commons 4.0 CC by. Política de archivado: etiqueta verde SHERPA-ROMEO. 
enseñar "su técnica" y "su estilo" particular, que en muchos casos pueden ser radicalmente diferentes a los de otros docentes. La pedagogía de la copia y de la imitación (Bandura, 1977), basada en modelos directos de enseñanza y aprendizaje, suele ser frecuentemente observada (Pozo et al., 2020). De hecho, un cambio de profesor suele implicar años de readaptación. Es frecuente ver estudiantes que, al acceder al conservatorio superior, necesitan invertir meses (incluso años) para adquirir la técnica del nuevo profesorado, retrocediendo a la práctica de ejercicios básicos, sin permitirles interpretar obras completas hasta adoptar dicha técnica. Esta es la manera en que el profesorado hace "suyo" al alumnado, esperando que le muestre total lealtad, como plantea Nettl (1995).

Es en este espacio tendente al adiestramiento y a la obediencia donde el profesor de instrumento inculca a sus estudiantes su propia visión de la música, desde una perspectiva cerrada y auto limitada, que prioriza la reproducción sobre la comprensión (Musumeci, 2005). Dichas actitudes y conductas implican mala praxis porque impiden el desarrollo creativo y artístico del alumnado, así como su autorregulación, metacognición, independencia y responsabilidad su propio aprendizaje (Jørgensen, 2000).

\subsection{El razonamiento sesgado: el músico nace y los problemas siempre son del alumnado}

Siguiendo a Herrán y González (2002), el razonamiento sesgado implica una tendencia a la protección y salvaguarda permanente del pensamiento propio, sin revisarlo de manera crítica. También implica una cierta incapacidad para objetivar los errores, tanto propios como colectivos. El docente que muestra dichas limitaciones en sus capacidades de razonamiento solo busca la opinión de otros compañeros (o figuras relevantes del contexto) para afianzar sus planteamientos previos, así como para obtener reconocimiento social. Dichas tendencias hacen que los enfoques pedagógicos del docente puedan desembocar en el adoctrinamiento del alumnado, incluso pudiendo alcanzar actitudes intolerantes y agresivas para justificar y defender sus planteamientos.

En la praxis del docente de música, el razonamiento sesgado se manifiesta en la típica creencia en que las dificultades de aprendizaje son siembre debidas al alumno, bien sea por su falta de talento o de esfuerzo (Pozo et al., 2020). Por el contrario, las deficiencias del propio profesor raramente se ponen sobre la mesa, ni se reflexiona (ni mucho menos se investiga) sobre cómo mejorar la propia practica docente. El mito del talento fue desacreditado hace décadas por la investigación en desarrollo de las habilidades musicales, que ha mostrado cómo alcanzar niveles altos de destreza instrumental requiere de un amplio rango de habilidades que se adquieren y desarrollan mediante la práctica estratégica continuada (Lehmann, Sloboda y Woody, 2011). Sin embargo, ciertos docentes no invierten esfuerzos tras diagnosticar que un alumno dado "no tiene talento", atribuyendo el fracaso en su aprendizaje únicamente a su falta de predisposiciones innatas (Judge, 2009).

@ Alfredo Bautista y Basilio Fernández Morante. The content of this article is the sole responsibility of the authors. The Revista Electrónica de LEEME and Universitat de València are not liable for any legal actions that may arise involving the article's content. Revista Electrónica de LEEME - Lista Electrónica Europea de Música en la Educación-. http://ojs.uv.es/index/php/LEEME/index ISSN: 1575-9563. Editores: Universidad de Valencia y Jesús Tejada. Visibilidad de esta revista: SCOPUS, Emerging Sources Citation Index (Clarivate), EBSCO, CINDOC (CSIC), Citefactor, COPAC, Dialnet, DICE (CSIC), DOAJ, e-revistas (CSIC), EBSCO Premier, ERIH+, Gale Cengage Learning, IN-RECS, IRESIE, LATINDEX, MIAR, OCLC Worldcat, RESH, REDIB, RILM Core Journals, SUDOC, ULRICHS. Esta revista es de acceso libre mediante licencia Creative Commons 4.0 CC by. Política de archivado: etiqueta verde SHERPA-ROMEO. 
En casos donde las dificultades de aprendizaje se atribuyen a la falta de estudio del estudiante, tienen incluso cabida conductas agresivas y violentas por parte del profesorado, conductas que lamentablemente son toleradas con frecuencia en contextos de educación artística, en particular en conservatorios (Fernández-Morante, 2018). Musumeci (2005) recopiló numerosos testimonios de niños que habían sido inducidos al llanto por sus primeros docentes de conservatorio, quienes manifestaron actitudes y conductas típicas de un enfoque educativo humanamente incompatible. En un estudio posterior, Musumeci (2008) acuñó el término violencia académica para referirse al profundo rechazo expresado por docentes de cursos superiores hacia estudiantes que suspendían sus exámenes de instrumento, quienes eran explícitamente calificados como incompetentes. Dicho estudio muestra que los ataques verbales y otros signos de violencia psicológica por parte del profesorado de instrumento suele tolerado por el alumnado, e incluso interpretados como útiles y necesarios, no siendo debidamente denunciados como signos de mala praxis (Fernández-Morante, 2018).

\section{Implicaciones para la formación docente}

Existen numerosos aspectos formativos, legislativos y estructurales que necesitan ser mejorados para combatir el desarrollo de los síntomas egóticos arriba descritos (narcisismo, egocentrismo, proxemia psíquica, razonamiento sesgado), y de este modo prevenir la mala praxis en educación instrumental. A continuación, proponemos diversas estrategias relativas a tres áreas clave.

\subsection{Perfilar la identidad profesional docente del profesorado de instrumento mediante una sólida formación pedagógica}

El énfasis en la interpretación que tradicionalmente ha existido en los currículos de las enseñanzas musicales en España todavía contribuye a generar entre los estudiantes la falsa expectativa de que su futuro profesional es el de intérprete, bien sea solista, en ensambles u orquestas. Sin embargo, dadas las demandas del mercado laboral, la realidad es que la mayoría de titulados terminan trabajando como docentes en conservatorios, escuelas municipales, academias, o institutos de enseñanza secundaria (Bernabé y Torres, 2017; Cid, 2012). Este hecho resulta insólito en gran medida, pues la formación pedagógica y didáctica ofrecida a los estudiantes suele ser nula durante el nivel profesional (Bautista, 2020). La reciente creación del itinerario de pedagogía en grado superior ha supuesto una mejora, en el sentido de otorgar importancia y espacio curricular formal a la formación docente. Sin embargo, la investigación indica que las concepciones de profesorado y alumnado aún no han cambiado sustancialmente como resultado de dicho nuevo itinerario (Pozo et al., 2020).

Dada la escasez de investigación en pedagogías y didácticas instrumentales específicas, dichas materias suelen enseñarse de forma abstracta y desconectada del aprendizaje de

@ Alfredo Bautista y Basilio Fernández Morante. The content of this article is the sole responsibility of the authors. The Revista Electrónica de LEEME and Universitat de València are not liable for any legal actions that may arise involving the article's content. Revista Electrónica de LEEME - Lista Electrónica Europea de Música en la Educación-. http://ojs.uv.es/index/php/LEEME/index ISSN: 1575-9563. Editores: Universidad de Valencia y Jesús Tejada. Visibilidad de esta revista: SCOPUS, Emerging Sources Citation Index (Clarivate), EBSCO, CINDOC (CSIC), Citefactor, COPAC, Dialnet, DICE (CSIC), DOAJ, e-revistas (CSIC), EBSCO Premier, ERIH+, Gale Cengage Learning, IN-RECS, IRESIE, LATINDEX, MIAR, OCLC Worldcat, RESH, REDIB, RILM Core Journals, SUDOC, ULRICHS. Esta revista es de acceso libre mediante licencia Creative Commons 4.0 CC by. Política de archivado: etiqueta verde SHERPA-ROMEO. 


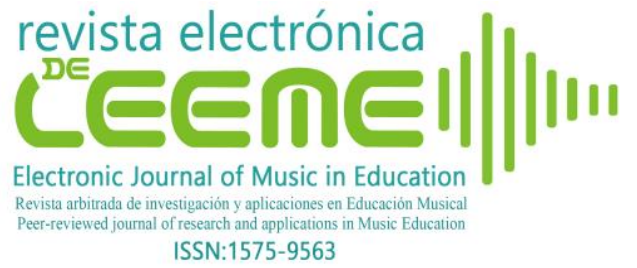

instrumentos musicales concretos (Bautista y Fernández-Morante, 2018). Ello resulta en una cantera de potenciales candidatos a docentes con una formación didáctica deficitaria (Cid, 2012), pero además con una identidad profesional como intérpretes, diferente por tanto de la profesión que la mayoría de estudiantes van a terminar desempeñando realmente (es decir, la docencia). Dichos desajustes muestran que, pese a las recientes reformas legislativas y curriculares, los conservatorios superiores no generan los perfiles profesionales que la sociedad demanda, fundamentalmente debido a la arraigada supremacía de la interpretación en los conservatorios, que contribuye a que el dominio de la técnica instrumental sea concebido implícitamente como el objetivo prioritario, tanto por docentes como discentes (Pozo et al., 2020).

Combatir los síntomas egóticos descritos anteriormente y evitar expectativas profesionales frustradas requiere perfilar la identidad docente del profesorado de instrumentos mediante una formación pedagógica y didáctica sólida, rigurosa y conectada con los trabajos que verdaderamente van a terminar desempeñando. Por ejemplo, síntomas como el narcisismo y el egocentrismo podrían reducirse mediante actividades donde los estudiantes analizan y reflexionan colaborativamente sobre vídeos de prácticas reales de clase. El uso de vídeos permite a los futuros docentes adentrarse en escenarios diversos de enseñanza y aprendizaje, observar las dimensiones instruccionales y socio-emocionales de las interacciones profesoralumno, y de este modo comenzar a desarrollar una incipiente identidad profesional docente (Bautista, Tan, Wong y Conway, 2019). Otra estrategia para combatir síntomas como el razonamiento sesgado implica la adquisición de competencias investigadoras, que informen y guíen la futura práctica profesional del profesorado de instrumentos. Enfoques como la Investigación-Acción (Campayo y Cabedo, 2018) o los Estudios de Clase (Lesson Study) (Akiba, Murata, Howard y Wilkinson, 2019; Wallbaum, 2018) son particularmente poderosos para fomentar la reflexión, el autoanálisis y la mejora de las estrategias empleadas en clase. Por ultimo, para combatir los síntomas egóticos arriba descritos sería recomendable ofrecer experiencias de practicum frecuentes y prolongadas (Mena, García, Clarke y Barkatsas, 2016), que permitan a los estudiantes tomar conciencia de la realidad profesional y requerimientos del docente, ofreciéndoles recursos apropiados (e.g., habilidades de manejo de la clase, gestión de las emociones y el estrés, identificación de estilos de enseñanza). Este tipo de experiencias formativas deberían ofrecerse desde las enseñanzas profesionales, puesto que éstas capacitan para enseñar en centros como academias y escuelas de música. Ofrecer dichas materias al menos como asignaturas optativas contribuiría a mejorar la escasa oferta curricular de tipo pedagógico/didáctico en las enseñanzas profesionales.

\subsection{Mejorar los procedimientos de selección e inducción a la profesión docente}

Una segunda área clave para combatir los síntomas egóticos entre el profesorado implica mejorar los actuales mecanismos de selección, pues la calidad de un sistema educativo 
nunca puede ser superior a la calidad de sus docentes (Darling-Hammond et al., 2017), así como mejorar los procedimientos de inducción a la docencia en centros de enseñanza musical. El sistema de oposiciones al cuerpo de profesorado de conservatorio en España es, a nuestro juicio, un sistema selectivo sesgado donde se prima la destreza técnica e interpretativa, se da una importancia reducida a las habilidades y conocimientos pedagógico y didácticos, y se ignoran en buena medida las dimensiones personales, actitudinales, motivacionales y socio-emocionales de los candidatos (Bautista, 2020). Las administraciones deberían reformar la lógica de los procesos selectivos y realizar una evaluación holística de los candidatos, dando una importancia equilibrada a dichos componentes, asegurando que el perfil de los candidatos presenta todas las competencias requeridas en un educador musical (Carrillo y Villar, 2014).

Además de los aspectos considerados actualmente, sería preciso valorar las motivaciones profesionales intrínsecas de los candidatos, sus habilidades sociales, sus estrategias de afrontamiento ante los problemas típicos de aula, así como sus capacidades para analizar y reflexionar sobre la práctica, y otros aspectos como la ansiedad escénica y los problemas de estudio (Bautista, 2020; Bújez, 2007; Guna, 2018; Torrado y Pozo, 2008). Sería también crucial valorar las competencias investigadoras de los candidatos, sus competencias para trabajar colaborativamente con otros docentes, para comunicarse con estudiantes, colegas y padres, y sus capacidades para asumir roles de liderazgo (Campayo y Cabedo, 2018). Por último, sería necesario realizar determinadas pruebas psicológicas para evitar el acceso a la profesión docente de personas con graves desequilibrios y trastornos, por su propio bienestar psicológico y el del alumnado (Fernández-Morante, 2018).

Es evidente que evaluar este tipo de competencias, habilidades, estrategias y características psicológicas requeriría utilizar múltiples fuentes de información, y que este modelo selectivo iría mucho mas allá de interpretar un repertorio, analizar una obra y defender una programación didáctica. Por ejemplo, se podría incluir pruebas como entrevistas individuales con los candidatos, requerirles ensayos donde elaboren sobre sus experiencias previas y expectativas futuras, testimonios de docentes, discentes y/o padres, así como portafolios con evidencias de su práctica docente (Cabedo, Juncos y Valero, 2015; Carrillo y Villar, 2014). Además, observar a los candidatos mientras dan una o varias clases a estudiantes reales (en tiempo real o a través de vídeos) sería ecológicamente más válido que diseñar y exponer programaciones didácticas alejadas de la realidad del aula (Bautista, 2020).

Para prevenir los síntomas que conducen a la mala praxis, es igualmente importante que los conservatorios y escuelas de música pongan en marcha mecanismos de inducción a la docencia y mentoría profesional (Portner, 2008). La investigación muestra que las experiencias de los docentes noveles durante sus primeros años de ejercicio son cruciales para su futuro desempeño, por lo que es necesario ofrecerles buenos modelos (Darling-Hammond et al., 2017). En los últimos años, ciertos conservatorios han introducido servicios de orientación profesional y psicopedagógica (Ponce de León y Lago, 2009), similares a los de los centros educativos

@ Alfredo Bautista y Basilio Fernández Morante. The content of this article is the sole responsibility of the authors. The Revista Electrónica de LEEME and Universitat de València are not liable for any legal actions that may arise involving the article's content. Revista Electrónica de LEEME - Lista Electrónica Europea de Música en la Educación-. http://ojs.uv.es/index/php/LEEME/index ISSN: 1575-9563. Editores: Universidad de Valencia y Jesús Tejada. Visibilidad de esta revista: SCOPUS, Emerging Sources Citation Index (Clarivate), EBSCO, CINDOC (CSIC), Citefactor, COPAC, Dialnet, DICE (CSIC), DOAJ, e-revistas (CSIC), EBSCO Premier, ERIH+, Gale Cengage Learning, IN-RECS, IRESIE, LATINDEX, MIAR, OCLC Worldcat, RESH, REDIB, RILM Core Journals, SUDOC, ULRICHS. Esta revista es de acceso libre mediante licencia Creative Commons 4.0 CC by. Política de archivado: etiqueta verde SHERPA-ROMEO. 


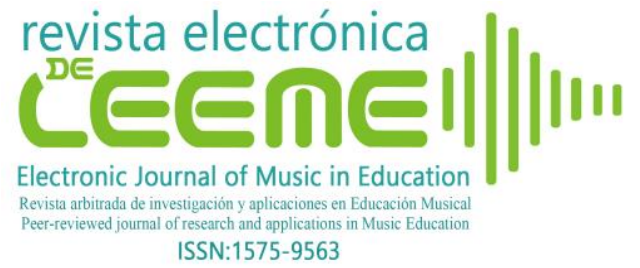

ordinarios. Pese a representar un importante avance, dicho modelo de orientación difiere del modelo de mentoría individualizada aquí propuesto. Todo educador musical novel debería ser guiado por un mentor experto que le induzca a la profesión y le apoye en las diferentes tareas a realizar, con especial énfasis en aquellas relativas a la enseñanza y el aprendizaje (Berg y Rickels, 2017). En vez de vigilar o controlar al nuevo docente, la función del mentor sería la de guiarlo en el análisis de la práctica pedagógica y sus desafíos, examinando juntos los resultados de aprendizaje del alumnado, y supervisando que el novel no reproduzca patrones de mala praxis a los que probablemente estuvo expuesto como alumno (Pozo et al., 2020; Torrado y Pozo, 2008). Además, el mentor acompañaría al docente novel en tareas relativas al diseño curricular y la investigación, la colaboración con otros colegas del centro, la administración y gestión y el propio desarrollo profesional (Berg y Rickels, 2017). Es evidente que esta estrategia requeriría contar con mentores capacitados para desempeñar sus funciones de forma efectiva (Portner, 2008), así como la creación de estructuras, tiempos y espacios para que los procesos de inducción y mentoría puedan producirse de forma sostenible.

\subsection{Fomentar el desarrollo profesional y el trabajo colaborativo}

Finalmente, otro antídoto contra los síntomas egóticos que conducen a la mala praxis en la enseñanza instrumental implica ofrecer más y mejores oportunidades de desarrollo profesional y fomentar el trabajo colaborativo. El tipo de oportunidades de formación permanente que suele ofrecerse al profesorado de instrumentos en conservatorios y escuelas de música (e.g., talleres de corta duración, generalmente no relacionados con las tareas docentes habituales y realizados fuera del centro, a título forma individual) son precisamente aquellas que los investigadores han descrito durante décadas como ineficaces, pues su impacto sobre las prácticas docentes y/o el aprendizaje del alumnado suele ser bajo o nulo (Desimone y Garet, 2015). La naturaleza individual y desconectada de la práctica de dichas iniciativas no contribuye a combatir síntomas como el egocentrismo o la proxemia psíquica, que resultan en un cierto aislamiento del profesor de instrumento. Como estrategia alternativa, proponemos que los cursos de formación permanente deberían proponerse, realizarse y gestionarse desde los centros, con la participación activa y la colaboración de los diversos los especialistas que lo integran, y que su diseño debería basarse en las características críticas del desarrollo profesional de alta calidad, asegurando la relevancia, rigor y sostenibilidad de dichas iniciativas formativas (Desimone y Garet, 2015).

Como se mencionó anteriormente, una estrategia crucial para prevenir la mala praxis implica que el profesorado convierta su práctica docente en objeto de reflexión, discusión e investigación. Recientemente, Campayo y Cabedo (2018) han aplicado los principios de la Investigación-Acción en el contexto de enseñanzas instrumentales, planteando que dicha metodología tiene gran potencial para ayudar al profesorado a cuestionar los métodos tradicionales y mejorar sus estrategias docentes. Este tipo de investigaciones, de orientación

@ Alfredo Bautista y Basilio Fernández Morante. The content of this article is the sole responsibility of the authors. The Revista Electrónica de LEEME and Universitat de València are not liable for any legal actions that may arise involving the article's content. Revista Electrónica de LEEME - Lista Electrónica Europea de Música en la Educación-. http://ojs.uv.es/index/php/LEEME/index ISSN: 1575-9563. Editores: Universidad de Valencia y Jesús Tejada. Visibilidad de esta revista: SCOPUS, Emerging Sources Citation Index (Clarivate), EBSCO, CINDOC (CSIC), Citefactor, COPAC, Dialnet, DICE (CSIC), DOAJ, e-revistas (CSIC), EBSCO Premier, ERIH+, Gale Cengage Learning, IN-RECS, IRESIE, LATINDEX, MIAR, OCLC Worldcat, RESH, REDIB, RILM Core Journals, SUDOC, ULRICHS. Esta revista es de acceso libre mediante licencia Creative Commons 4.0 CC by. Política de archivado: etiqueta verde SHERPA-ROMEO. 


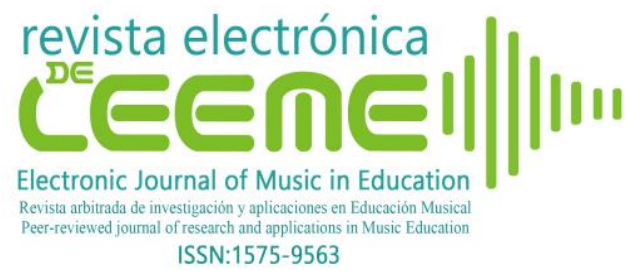

aplicada, permitiría combatir el síntoma egótico del razonamiento sesgado, ayudando al profesorado a comprender que el aprendizaje del alumnado depende en gran medida de su propia labor pedagógica, y que el talento musical no es tan determinante como muchos docentes creen (Lehmann et al., 2011). Lamentablemente, este tipo de investigaciones no se realizan en muchos conservatorios y escuelas de música, donde el profesorado tiende a trabajar aislado, reflejando los síntomas egocéntricos arriba descritos, siendo muy celoso de lo que sucede en sus respectivas aulas, bien por evitar críticas de otros colegas o por no querer compartir lo que sabe/hace con el alumnado (Bautista y Fernández-Morante, 2018). Entre otras consecuencias, esta falta de comunicación y trabajo colaborativo resulta en falta de renovación pedagógica, que se refleja en el uso constante de los mismos materiales y recursos de enseñanza/aprendizaje (e.g., mismo repertorio, dinámicas de aula, metodologías). Este hecho resulta paradójico en unas enseñanzas de naturaleza artística, donde la exploración y la creatividad deberían ser la tónica dominante (Pozo et al., 2020).

Finalmente, para prevenir la mala praxis en conservatorios y escuelas de música sería positivo establecer colaboraciones interdisciplinares con agentes externos (e.g., otras instituciones educativas, orquestas, asociaciones profesionales, compañías productoras, órganos de publicación), para garantizar que el profesorado es consciente de las competencias que la sociedad y el mercado laboral demandará a sus estudiantes en el futuro cercano (Ponce de León y Lago, 2009). Los tiempos cambian, las artes avanzan, y los instrumentistas necesitan estar preparados para adaptarse a dichos cambios. Los docentes deben ampliar su espacio de proxemia psíquica, relacionarse con el mundo exterior, y ofrecer al estudiantado una formación integral, no solo a nivel técnico e interpretativo. Como plantean Bernabé y Torres (2017), ello requiere mirar hacia afuera y ser conscientes de las demandas laborales, sociales, económicas y tecnológicas del siglo XXI.

\section{Conclusiones y reflexiones finales}

En este artículo, se ha revisado la limitada literatura educativa centrada en la noción de educational malpractice, producida esencialmente en el contexto norteamericano (Foster, 1986; Funston, 1981; Heyneman, 2004; Martin, 2016; Tanaka, 2001). Se argumenta que marco teórico propuesto por Herrán y González (2002) presenta gran potencial para explicar ciertas problemáticas observadas en contextos de enseñanza instrumental formal, cuyo marcado carácter individualista (producto del modelo de enseñanza one-to-one) fomenta el aislamiento y en ocasiones el egocentrismo, con el consiguiente riesgo de desembocar en casos de malas prácticas de aula (e.g., Herrán, 1995; Herrán y Fortunato, 2019; Herrán y González, 2002, 2003; Socorro, 2011; Socorro y Herrán, 2012).

Se han definido algunos de los síntomas egóticos que, de acuerdo con Herrán y González (2002), tienden a desembocar en mala praxis, y se han ejemplificado cómo pueden

@Alfredo Bautista y Basilio Fernández Morante. The content of this article is the sole responsibility of the authors. The Revista Electrónica de LEEME and Universitat de València are not liable for any legal actions that may arise involving the article's content. Revista Electrónica de LEEME - Lista Electrónica Europea de Música en la Educación-. http://ojs.uv.es/index/php/LEEME/index ISSN: 1575-9563. Editores: Universidad de Valencia y Jesús Tejada. Visibilidad de esta revista: SCOPUS, Emerging Sources Citation Index (Clarivate), EBSCO, CINDOC (CSIC), Citefactor, COPAC, Dialnet, DICE (CSIC), DOAJ, e-revistas (CSIC), EBSCO Premier, ERIH+, Gale Cengage Learning, IN-RECS, IRESIE, LATINDEX, MIAR, OCLC Worldcat, RESH, REDIB, RILM Core Journals, SUDOC, ULRICHS. Esta revista es de acceso libre mediante licencia Creative Commons 4.0 CC by. Política de archivado: etiqueta verde SHERPA-ROMEO. 
manifestarse en los conservatorios y escuelas de música. Se ha postulado que los síntomas que conducen a la mala praxis en esta área podrían comenzar a gestarse desde la propia formación inicial, centrada primordialmente en las competencias interpretativas, lo cual podría favorecer tendencias narcisistas. Una tradición pedagógica donde el profesor se concibe como figura central, como maestro a seguir e imitar, podría dar lugar a pautas de comportamiento egocéntricas, estableciendo espacios proxémicos donde mostrar libremente dichas pautas, sobre la base de mitos como el del talento y otras falacias producidas por sesgos de pensamiento diversos. Los ejemplos mostrados han dado cuenta de la íntima conexión entre los diversos síntomas egóticos descritos.

Seguidamente, se ha argumentado que existen numerosos aspectos que necesitan ser mejorados para combatir los síntomas egóticos y prevenir la mala praxis en las enseñanzas instrumentales, y se han propuesto estrategias de actuación centradas en (1) perfilar la identidad profesional docente mediante una sólida formación pedagógica, (2) mejorar los procedimientos de selección e inducción a la profesión docente, y (3) fomentar el desarrollo profesional y el trabajo colaborativo. Las diversas estrategias sugeridas implican cambios a diversos niveles, tanto individual (creencias y prácticas de cada profesor), grupal (dinámicas de trabajo en equipos docentes), institucional (mecanismos para fomentar el desarrollo permanente), así como legislativo (procesos de selección e inducción del profesorado) (Bautista, 2020). Poner en práctica dichas estrategias requerirá una compleja labor de andamiaje y de trabajo colaborativo entre profesorado, mentores, equipos docentes y directivos, así como investigadores, legisladores, políticos educativos y otros profesionales externos (Darling-Hammond et al., 2017). El desafío es ayudar al profesorado salir de las dinámicas de trabajo tradicionales, centradas en el egocentrismo, el individualismo y la competitividad, mostrando que trabajar de forma cooperativa es mucho más productivo y beneficioso para fomentar el desarrollo integral y la creatividad de los estudiantes (Pozo et al., 2020). Las diversas estrategias propuestas serían también beneficiosas para prevenir el burnout (o síndrome del profesor quemado) que obstaculiza seriamente el desarrollo profesional del profesorado de conservatorios (McPherson y Welch, 2018).

A modo de reflexiones finales, uno de los primeros pasos para combatir los síntomas egóticos y prevenir la mala praxis en conservatorios y escuelas de música implica repensar cuál es el objetivo último de las enseñanzas instrumentales en nuestra sociedad actual (McPherson y Welch, 2018). Los síntomas egóticos caracterizados en este artículo tienen como base la expectativa (explícita o implícita) de formar al alumnado como instrumentistas (e.g., concertistas), con altos requerimientos a nivel reproductivo y técnico, para poder destacar en el competitivo mundo de la interpretación. Sin embargo, como se ha argumentado, dicha expectativa es irreal porque la mayoría de graduados de conservatorios acaban desempeñando otras profesiones, pese a no haber sido adecuadamente formados para ejercerlas (Bernabé y Torres, 2017; Cid, 2012).

@ Alfredo Bautista y Basilio Fernández Morante. The content of this article is the sole responsibility of the authors. The Revista Electrónica de LEEME and Universitat de València are not liable for any legal actions that may arise involving the article's content. Revista Electrónica de LEEME - Lista Electrónica Europea de Música en la Educación-. http://ojs.uv.es/index/php/LEEME/index ISSN: 1575-9563. Editores: Universidad de Valencia y Jesús Tejada. Visibilidad de esta revista: SCOPUS, Emerging Sources Citation Index (Clarivate), EBSCO, CINDOC (CSIC), Citefactor, COPAC, Dialnet, DICE (CSIC), DOAJ, e-revistas (CSIC), EBSCO Premier, ERIH+, Gale Cengage Learning, IN-RECS, IRESIE, LATINDEX, MIAR, OCLC Worldcat, RESH, REDIB, RILM Core Journals, SUDOC, ULRICHS. Esta revista es de acceso libre mediante licencia Creative Commons 4.0 CC by. Política de archivado: etiqueta verde SHERPA-ROMEO. 


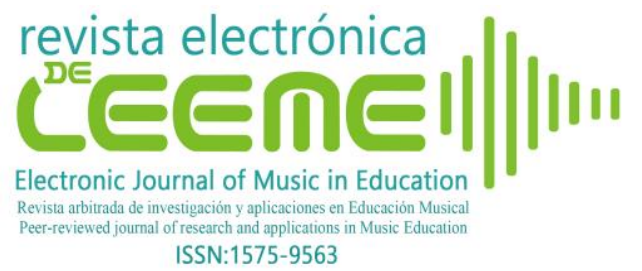

Tocar bien un extenso repertorio de piezas nunca debería ser el único objetivo para discentes (y docentes) de instrumento, ni tampoco el más importante, pues un énfasis excesivo en este aspecto deja de lado otros objetivos igualmente importantes, o incluso más, como facilitar el desarrollo de la creatividad musical, fomentar la expresión y/o comunicación emocional, o simplemente promover el disfrute del alumnado a través de la música. Se cuestiona, por tanto, la pertinencia de otorgar carácter profesionalizador a las enseñanzas actualmente denominadas 'profesionales', pues ello contribuye a que se perpetúe la cultura tradicional de aprendizaje directo en los conservatorios y escuelas de música (Pozo et al., 2020).

Finalmente, respecto a las enseñanzas superiores, se sugiere la creación de un mayor número de itinerarios curriculares, más allá del clásico binomio Interpretación vs Pedagogía, que provea al alumnado de una preparación de calidad, mejor alineada con las profesiones relacionadas con la música que demanda la sociedad en el siglo XXI (Carrillo y Villar, 2014; Ford, 2010; Ponce de León y Lago, 2009). Un mejor ajuste de objetivos, metas y expectativas, sumado a una mejor formación docente, contribuirán a combatir los síntomas egóticos del interesante marco de mala praxis de Herrán y González (2002) en las enseñanzas instrumentales.

\section{Financiación y agradecimientos}

El presente estudio es parte del proyecto SRSF2018/19-001 (Strategic Research Funding Scheme), financiado por el Department of Early Childhood Education en The Education University of Hong Kong.

\section{Referencias}

Akiba, M., Murata, A., Howard, C.C. y Wilkinson, B. (2019). Lesson study design features for supporting collaborative teacher learning. Teaching and Teacher Education, 77, 352365. doi:10.1016/j.tate.2018.10.012

Bandura, A. (1977). Social learning theory. Nueva York, NY: General Learning Press.

Bautista, A. (2020). Formación y desarrollo profesional en docentes de interpretación musical: Propuestas para cambiar concepciones y prácticas. En J.I. Pozo, M.P. Pérez Echeverría, J.A. Torrado, y G. López-Íñiguez (Eds.), Aprender y enseñar música. Un enfoque centrado en los alumnos (pp.381-410). Madrid, Spain: Ediciones Morata.

Bautista, A. y Fernández-Morante, B. (2018). Monográfico sobre investigación en interpretación musical: Implicaciones para el desarrollo profesional docente. Psychology, Society, and Education, 10(1), 1-13. doi:10.25115/psye.v10i1.1869 
Bautista, A., Tan, C., Wong, J. y Conway, C. (2019). The role of classroom video in music teacher research: A review of the literature. Music Education Research, 21(4), 331-343. doi:10.1080/14613808.2019.1632278

Berg, M.H. y Rickels, D.A. (2017). Mentoring for mentors: The music mentor plus program. Journal of Music Teacher Education, 27(2), 39-51. doi:10.1177/1057083717720634

Bernabé, M. y Torres, M. (2017). ¿Qué formación didáctica recibe el futuro profesorado de clarinete en el grado superior? Reflexiones y propuesta curricular. Arbor, 193(783), a373. doi:10.3989/arbor.2017.783n1004

Boote, D.N. y Beile, P. (2005). Scholars before researchers: On the centrality of the dissertation literature review in research preparation. Educational Researcher, 34(6), 3-15. doi:10.3102/0013189X034006003

Bújez, A. (2007). Evaluación del currículo en los conservatorios de grado superior de música de Andalucía. Granada: Universidad de Granada.

Burwell, K. (2005). A degree of independence: Teachers approaches to instrumental tuition in a university college. British Journal of Music Education, 22(3), 199-215. doi:10.1017/S0265051705006601

Burwell, K., Carey, G. y Bennett, D. (2019). Isolation in studio music teaching: The secret garden. Arts and Humanities in Higher Education, 18(4), 372-394. doi:10.1177/1474022217736581

Cabedo, C., Juncos, R. y Valero, J.P. (2015). Las enseñanzas de música y danza en la Comunidad Valenciana. Marco teórico para su evaluación desde un modelo de cohesión social. Valencia: Generalitat Valenciana.

Campayo, E. y Cabedo, A. (2018). Investigación-acción como recurso para la innovación y mejora de la práctica educativa en conservatorios: una experiencia en las enseñanzas elementales de música en España. Psychology, Society, and Education, 10(1), 15-36. doi:10.25115/psye.v10i1.1767

Carrillo, C. y Villar, M. (2014). El perfil profesional del profesorado de música: una propuesta de las competencias deseables en Ed. Primaria y Ed. Secundaria. Revista Electrónica de LEEME, 33, 1-26. Recuperado de: ojs.uv.es/index.php/LEEME/article/view/9856/9276

Castillo, M., Ramos Corpas, M.J. y Moral, G. (2020). Buenas prácticas en la organización, gestión y dirección de los centros educativos. Bordón. Revista de Pedagogía, 72(1), 1130. doi:10.13042/Bordon.2020.01.63135

@ Alfredo Bautista y Basilio Fernández Morante. The content of this article is the sole responsibility of the authors. The Revista Electrónica de LEEME and Universitat de València are not liable for any legal actions that may arise involving the article's content. Revista Electrónica de LEEME - Lista Electrónica Europea de Música en la Educación-. http://ojs.uv.es/index/php/LEEME/index ISSN: 1575-9563. Editores: Universidad de Valencia y Jesús Tejada. Visibilidad de esta revista: SCOPUS, Emerging Sources Citation Index (Clarivate), EBSCO, CINDOC (CSIC), Citefactor, COPAC, Dialnet, DICE (CSIC), DOAJ, e-revistas (CSIC), EBSCO Premier, ERIH+, Gale Cengage Learning, IN-RECS, IRESIE, LATINDEX, MIAR, OCLC Worldcat, RESH, REDIB, RILM Core Journals, SUDOC, ULRICHS. Esta revista es de acceso libre mediante licencia Creative Commons 4.0 CC by. Política de archivado: etiqueta verde SHERPA-ROMEO. 
Cid, M.J. (2012). Los conservatorios superiores de Galicia durante la LOGSE. Revista Electrónica de LEEME. Lista Electrónica Europea de Música en la Educación, 29, 122. Recuperado de: ojs.uv.es/index.php/LEEME/article/view/9833

Darling-Hammond, L., Burns, D., Campbell, C., Goodwin, A.L., Hammerness, K., Low, E.-L. y Zeichner, M. (2017). Empowered educators: How high-performing systems shape teaching quality around the world. New York, NY: John Wiley \& Sons.

Desimone, L.M. y Garet, M.S. (2015). Best practices in teachers' professional development in the United States. Psychology, Society and Education, 7(3), 252-263. doi:10.25115/psye.v7i3.515

Dumitrescu, R. (2019). The approach of medical malpractice phenomenon within theoretical framework of medical sociology. Jurnalul Practicilor Comunitare Pozitive, 19(4), 4679. doi:10.35782/JCPP.2019.4.04

Escudero, J.M. (2009). Buenas prácticas y programas extraordinarios de atención al alumnado en riesgo de exclusión educativa. Profesorado. Revista de Currículum y Formación de Profesorado, 13(3), 107-141. Recuperado de: http://www.ugr.es/ recfpro/

Fernández-Morante, B. (2018). Violencia psicológica en la educación musical actual en los conservatorios de música. Revista Internacional de Educación Musical, 6(1), 13-24. doi:10.12967/RIEM-2018-6-p013-024

Ford, B. (2010). What are conservatoires for? Discourses of purpose in the contemporary conservatoire. (Tesis Doctoral). Londres, UK: Institute of Education, University of London.

Foster, W.F. (1986). Educational malpractice: educate or litigate. Canadian Journal of Education, 11(2), 122-151. doi:10.2307/149480

Funston, R. (1981). Educational malpractice: a cause of action in search of a theory. San Diego Law Review, 18(5), 743-812. Recuperado de: http://id.loc.gov/authorities/

Glasser, B.G. (2001). The grounded theory perspective: conceptualization contrasted with descr iption. Mill Valley, CA: Sociology Press.

Guna, M. (2018). Desarrollo profesional docente del profesorado de enseñanzas musicales de conservatorio de tuba en España. Contexto sociopolítico e institucional. Edetania. Estudios y Propuestas Socioeducativas, 54, 223-246. Recuperado de: https://revistas.ucv.es/index.php/Edetania/article/view/403

@ Alfredo Bautista y Basilio Fernández Morante. The content of this article is the sole responsibility of the authors. The Revista Electrónica de LEEME and Universitat de València are not liable for any legal actions that may arise involving the article's content. Revista Electrónica de LEEME - Lista Electrónica Europea de Música en la Educación-. http://ojs.uv.es/index/php/LEEME/index ISSN: 1575-9563. Editores: Universidad de Valencia y Jesús Tejada. Visibilidad de esta revista: SCOPUS, Emerging Sources Citation Index (Clarivate), EBSCO, CINDOC (CSIC), Citefactor, COPAC, Dialnet, DICE (CSIC), DOAJ, e-revistas (CSIC), EBSCO Premier, ERIH+, Gale Cengage Learning, IN-RECS, IRESIE, LATINDEX, MIAR, OCLC Worldcat, RESH, REDIB, RILM Core Journals, SUDOC, ULRICHS. Esta revista es de acceso libre mediante licencia Creative Commons 4.0 CC by. Política de archivado: etiqueta verde SHERPA-ROMEO. 
Gupta, A. (2018). How neoliberal globalization is shaping early childhood education policies in India, China, Singapore, Sri Lanka and the Maldives. Policy Futures in Education, 16(1), 11-28. doi:10.1177/1478210317715796

Hallak, J. y Poisson, M. (2007). Corrupt schools, corrupt universities: What can be done? Paris, France: International Institute for Education Planning.

Herrán, A. (1995). Ego, autoconocimiento y conciencia: Tres ámbitos en la formación básica y la evolución personal de los profesores. Madrid: Universidad Complutense de Madrid.

Herrán, A. (2011). Reflexiones para una reforma profunda de la educación, desde un enfoque basado en la complejidad, la universalidad y la conciencia. Educación XX1, 14, 245264. Recuperado de: https://www.redalyc.org/articulo.oa?id=70618224011

Herrán, A. (2014). Creatividad y formación radical e inclusiva: cuando la creatividad no sirve para nada. Granada: Universidad de Granada.

Herrán, A. (2017). La 'mala práctica' educativa desde el enfoque radical de la formación. Boletín del Ilustre Colegio Oficial de Doctores y Licenciados en Filosofía y Letras y en Ciencias de Madrid, 267, 10-12. doi:10.36260/rbr.v8i4.724

Herrán, A. y Fortunato, I. (2019). ¿Por qué desde la didáctica no se favorece la formación del profesorado? Pro-Posições, 30, 1-32. doi:10.1590/1980-6248-2017-0033

Herrán, A. y González, I. (2002). El ego docente, punto ciego de la enseñanza, el desararollo profesional y la formación del profesorado. Madrid: Universitas.

Herrán, A. y González, I. (2003). (EGO)Centrismo docente y enseñanza inmadura. Indivisa, Boletín de Estudios e Investigación, 4, 51-57. Recuperado de: http://hdl.handle.net/

Heyneman, S.P. (2004). Education and corruption. International Journal of Educational Development, 24(6), 637-648. doi:10.1016/j.ijedudev.2004.02.005

Jørgensen, H. (2000). Student learning in higher instrumental education: who is responsible? British Journal of Music Education, 17(1), 67-77. doi:10.1017/S0265051700000164

Judge, J. (2009). Musical talent: born genius? The American Music Teacher, 58(5), 14-21. Recuperado de: https://www.jstor.org/stable/43549551

Kogan, J. (1987). Nothing but the best. The struggle for perfection at the Julliard School. Nueva York: Random House.

Lehmann, A.C., Sloboda, J.A. y Woody, R.H. (2011). Psychology for musicians: understanding and acquiring the skills. Oxford, UK: Oxford Scholarship Online.

@ Alfredo Bautista y Basilio Fernández Morante. The content of this article is the sole responsibility of the authors. The Revista Electrónica de LEEME and Universitat de València are not liable for any legal actions that may arise involving the article's content. Revista Electrónica de LEEME - Lista Electrónica Europea de Música en la Educación-. http://ojs.uv.es/index/php/LEEME/index ISSN: 1575-9563. Editores: Universidad de Valencia y Jesús Tejada. Visibilidad de esta revista: SCOPUS, Emerging Sources Citation Index (Clarivate), EBSCO, CINDOC (CSIC), Citefactor, COPAC, Dialnet, DICE (CSIC), DOAJ, e-revistas (CSIC), EBSCO Premier, ERIH+, Gale Cengage Learning, IN-RECS, IRESIE, LATINDEX, MIAR, OCLC Worldcat, RESH, REDIB, RILM Core Journals, SUDOC, ULRICHS. Esta revista es de acceso libre mediante licencia Creative Commons 4.0 CC by. Política de archivado: etiqueta verde SHERPA-ROMEO. 
Martin, M. (2016). External quality assurance in higher education: How can it address corruption and other malpractices? Quality in Higher Education, 22(1), 49-63. doi:10.1080/13538322.2016.1144903

McPherson, G. y Welch, G. (Eds.). (2018). Vocal, instrumental, and ensemble learning and teaching: an Oxford handbook of music education (Vol.3). Oxford, UK: Oxford University Press.

Mena, J., García, M., Clarke, A. y Barkatsas, A. (2016). An analysis of three different approaches to student teacher mentoring and their impact on knowledge generation in practicum settings. European Journal of Teacher Education, 39(1), 53-76. doi:10.1080/02619768.2015.1011269

Miksza, P., Evans, P. y McPherson, G.E. (2019a). Motivation to pursue a career in music: The role of social constraints in university music programs. Psychology of Music, 47(2), 119. doi:10.1177/0305735619836269

Miksza, P., Evans, P. y McPherson, G. E. (2019b). Wellness among university-level music students: a study of the predictors of subjective vitality. Musicae Scientiae, 1-18. doi: $10.1177 / 1029864919860554$

Musumeci, O. (2005). Audioperceptiva humanamente compatible. Eufonía, 34, 44-59. Recuperado de: https://dialnet.unirioja.es/ejemplar/108728

Musumeci, O. (2006). Los conservatorios desde una perspectiva sociocultural y su relación con los individuos. Buenos Aires, Argentina: UCA.

Musumeci, O. (2008). Dos exámenes (uno ficticio), dos entrevistas (una fallida) y varias víctimas: violencia académica en un Conservatorio y la representatividad y legitimidad de la investigación. En M. Espejo (Ed.), Primer encuentro internacional de investigación en música (pp.138-159). Tunja, Colombia: UPTC.

Nettl, B. (1995). Heartland excursions: Ethnomusicological reflections on schools of music (Vol.415). Urbana: University of Illinois Press.

Pérez Porto, J. y Gardey, A. (2018). Definición de mala praxis. Recuperado de: https://definicion.de/mala-praxis/

Persson, R.S. (2001). The subjective world of the performer. En P. Juslin y J. Sloboda (Eds.), Music and emotion, theory and research (pp.275-289). Nueva York: Oxford University Press.

@ Alfredo Bautista y Basilio Fernández Morante. The content of this article is the sole responsibility of the authors. The Revista Electrónica de LEEME and Universitat de València are not liable for any legal actions that may arise involving the article's content. Revista Electrónica de LEEME - Lista Electrónica Europea de Música en la Educación-. http://ojs.uv.es/index/php/LEEME/index ISSN: 1575-9563. Editores: Universidad de Valencia y Jesús Tejada. Visibilidad de esta revista: SCOPUS, Emerging Sources Citation Index (Clarivate), EBSCO, CINDOC (CSIC), Citefactor, COPAC, Dialnet, DICE (CSIC), DOAJ, e-revistas (CSIC), EBSCO Premier, ERIH+, Gale Cengage Learning, IN-RECS, IRESIE, LATINDEX, MIAR, OCLC Worldcat, RESH, REDIB, RILM Core Journals, SUDOC, ULRICHS. Esta revista es de acceso libre mediante licencia Creative Commons 4.0 CC by. Política de archivado: etiqueta verde SHERPA-ROMEO. 
Ponce de León, L. y Lago, P. (2009). Necesidades de orientación en los conservatorios profesionales de música. Revista Electrónica de LEEME, 24, 63-76. doi:10.4438/1988592X-RE-2011-359-096

Portner, H. (2008). Mentoring new teachers. Thousand Oaks, CA: Corwin Press.

Pozo, J.I., Pérez Echeverría, M.P., Torrado, J.A. y López-Iñniguez, G. (Eds.). (2020). Aprender y enseñar música. Un enfoque centrado en los alumnos. Madrid: Morata.

Silva, H. (2008). Responsabilidad penal por actos culposos de los médicos en el ejercicio de su profesión. Revista de Derecho y Ciencias Penales, 11, 121-129. Recuperado de: https://rduss.com/index.php/rduss/article/view/187/133

Socorro, M. (2011). La madurez personal como base del desarrollo profesional del docente. Madrid: Universidad Autónoma de Madrid.

Socorro, M. y Herrán, A. (2012). La madurez en el desarrollo profesional del docente. Revista Iberoamericana sobre Calidad, Eficacia y Cambio en Educación, 10(3), 26-44. Recuperado de: https://revistas.uam.es/reice/article/view/3039/3252

Szabolcs, B., Sándor, N. y László, N. (2017). The narcissism of classical and pop musicians: an exploratory study. Interdiszciplináris Doktorandusz Konferencia, VI, 19-21. doi:10.13140/RG.2.2.10427.41764

Tanaka, S. (2001). Corruption in education sector development: a suggestion for anticipatory strategy. International Journal of Educational Management, 15(4), 158-166. Recuperado de: https://www.ingentaconnect.com/content/mcb/060/2001

Torrado, J.A. y Pozo, J.I. (2008). Metas y estrategias para una práctica constructiva en la enseñanza instrumental. Cultura y Educacion, 20(1), 35-48. doi: $10.1174 / 113564008783781468$

Tregear, P., Johansen, G., Jørgensen, H., Sloboda, J., Tulve, H. y Wistreich, R. (2016). Conservatoires in society: institutional challenges and possibilities for change. Arts and Humanities in Higher Education, 15(3-4), 276-292. doi: 10.1177/1474022216647379

Villegas, Z. (2016). Prácticas y praxis de investigación en las universidades. Revista de Ciencias de la Educación, 26, 347-359. Recuperado de: http://servicio.bc.uc.edu.ve/educacion/revista/48/art20.pdf

Wallbaum, C. (Ed.) (2018). Comparing international music lessons on video. Nueva York, NY: Georg Olms Verlag.

@ Alfredo Bautista y Basilio Fernández Morante. The content of this article is the sole responsibility of the authors. The Revista Electrónica de LEEME and Universitat de València are not liable for any legal actions that may arise involving the article's content. Revista Electrónica de LEEME - Lista Electrónica Europea de Música en la Educación-. http://ojs.uv.es/index/php/LEEME/index ISSN: 1575-9563. Editores: Universidad de Valencia y Jesús Tejada. Visibilidad de esta revista: SCOPUS, Emerging Sources Citation Index (Clarivate), EBSCO, CINDOC (CSIC), Citefactor, COPAC, Dialnet, DICE (CSIC), DOAJ, e-revistas (CSIC), EBSCO Premier, ERIH+, Gale Cengage Learning, IN-RECS, IRESIE, LATINDEX, MIAR, OCLC Worldcat, RESH, REDIB, RILM Core Journals, SUDOC, ULRICHS. Esta revista es de acceso libre mediante licencia Creative Commons 4.0 CC by. Política de archivado: etiqueta verde SHERPA-ROMEO. 


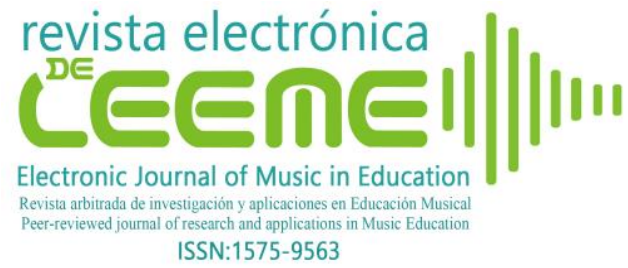

Young, L.J. (2001). Border crossings and other journeys: Re-envisioningthe doctoral preparation of education researchers. Educational Researcher, 30(5), 3-5. doi:10.3102/0013189X030005003

Zabalza, M.A. (2012). El estudio de las "buenas prácticas" docentes en la enseñanza universitaria. Revista de Docencia Universitaria. REDU, 10(1), 17-42. doi:10.4995/redu.2012.6120 